\title{
Risk factor management in a contemporary Australian population at increased cardiovascular disease risk
}

D. J. Campbell, ${ }^{1,2,3}$ J. M. Coller, ${ }^{3}$ F. F. Gong, ${ }^{1,2,3}$ M. McGrady, ${ }^{4}$ D. L. Prior, ${ }^{2,3}$ U. Boffa, ${ }^{4}$ L. Shiel, ${ }^{4}$ D. Liew, ${ }^{4}$ R. Wolfe, ${ }^{4}$ A. J. Owen, ${ }^{4}$ H. Krum $^{4 *}$ and C. M. Reid ${ }^{4,5}$

${ }^{1}$ St. Vincent's Institute of Medical Research, ${ }^{2}$ University of Melbourne, ${ }^{3}$ St. Vincent's Hospital, Melbourne, ${ }^{4}$ School of Public Health and Preventive Medicine, Monash University, ${ }^{5}$ School of Public Health, Curtin University

*Deceased

Short title: Risk factor management

Correspondence:

Duncan J. Campbell

St. Vincent's Institute of Medical Research

41 Victoria Parade, Fitzroy, Victoria 3065, Australia

Tel: 0392882501

Fax: 0394162676

Email: dcampbell@svi.edu.au

This is the author manuscript accepted for publication and has undergone full peer review but has not been through the copyediting, typesetting, pagination and proofreading process, which may lead to differences between this version and the Version of Record. Please cite this article as doi: 10.1111/imj.13678

This article is protected by copyright. All rights reserved. 
Word count (main text): 3046

This article is protected by copyright. All rights reserved. 


\begin{abstract}
Background: Effective management of cardiovascular and chronic kidney disease risk factors offers longer, healthier lives and savings in health care. We examined risk factor management in participants of the SCReening Evaluation of the Evolution of New Heart Failure (SCREEN-HF) study, a self-selected population at increased cardiovascular disease risk recruited from members of a health insurance fund in Melbourne and Shepparton, Australia.
\end{abstract}

Methods: Inclusion criteria were age e 60 years with one or more of self-reported ischaemic or other heart disease, irregular or rapid heart rhythm, cerebrovascular disease, renal impairment, or treatment for hypertension or diabetes for e 2 years. Exclusion criteria were known heart failure or cardiac abnormality on echocardiography or other imaging. Medical history, clinical examination, full blood examination and biochemistry (without lipids and HbA1c) were performed for 3847 participants on enrolment, and blood pressure, lipids and HbA1c were measured 1-2 years after enrolment for 3202 participants.

Results: Despite 99\% of 3294 participants with hypertension receiving antihypertensive medication, half had blood pressures $>140 / 90 \mathrm{mmHg}$. Approximately $77 \%$ of participants were overweight or obese, with one third obese. Additionally, $74 \%$ of participants at high cardiovascular disease risk had low density lipoprotein cholesterol levels e $2 \mathrm{mmol} / \mathrm{l}$, one third of diabetic participants had $\mathrm{HbA} 1 \mathrm{c}>7 \%, 22 \%$ had estimated glomerular filtration rate $<60 \mathrm{ml} / \mathrm{min} / 1.73 \mathrm{~m}^{2}$, and substantial proportions had under-utilisation of antiplatelet therapy, anticoagulation for atrial fibrillation, and were physically inactive. 
Conclusions: This population demonstrated substantial potential to reduce cardiovascular and renal morbidity and mortality and health care costs through more effective management of modifiable risk factors.

This article is protected by copyright. All rights reserved. 


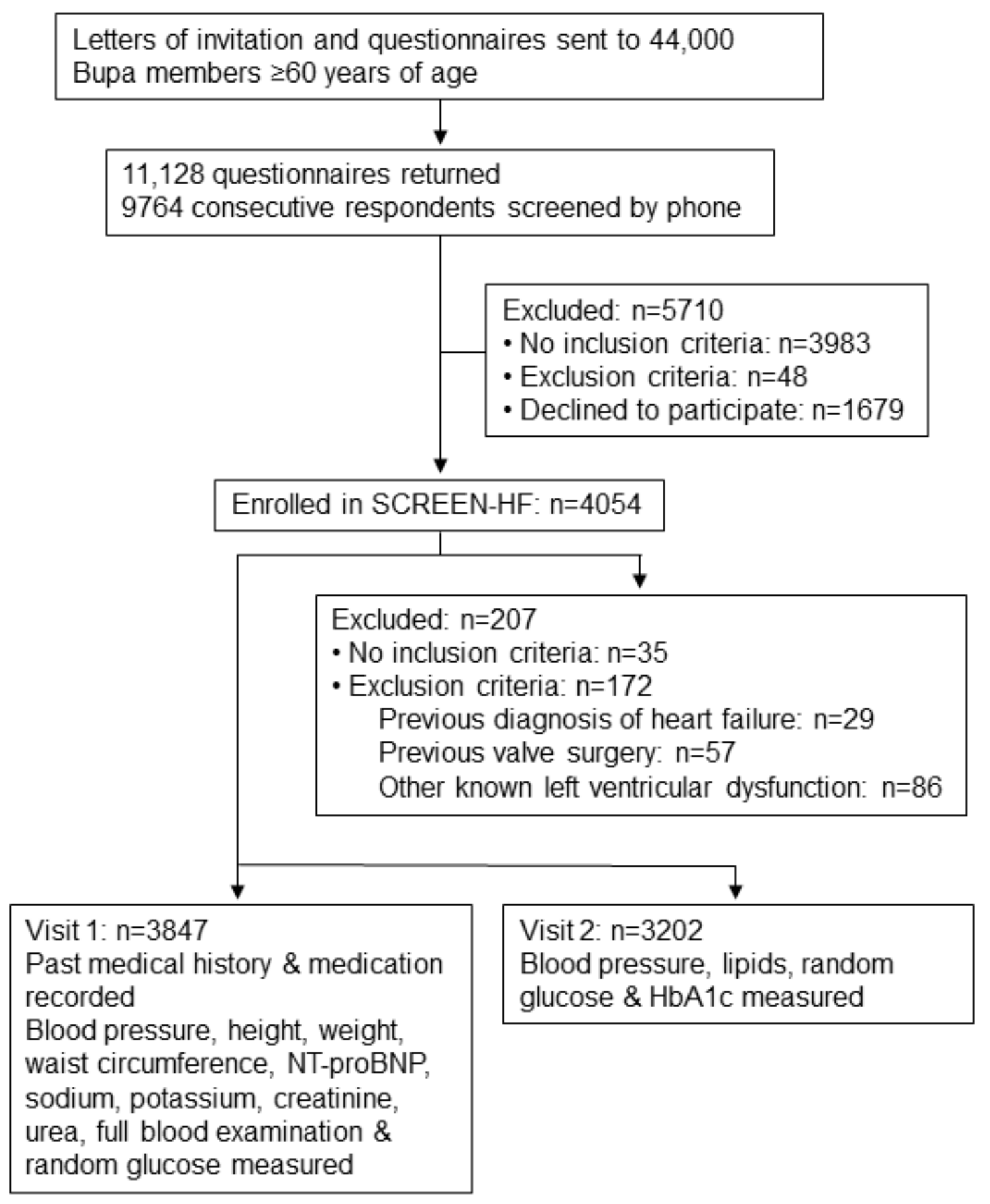

This article is protected by copyright. All rights reserved. 


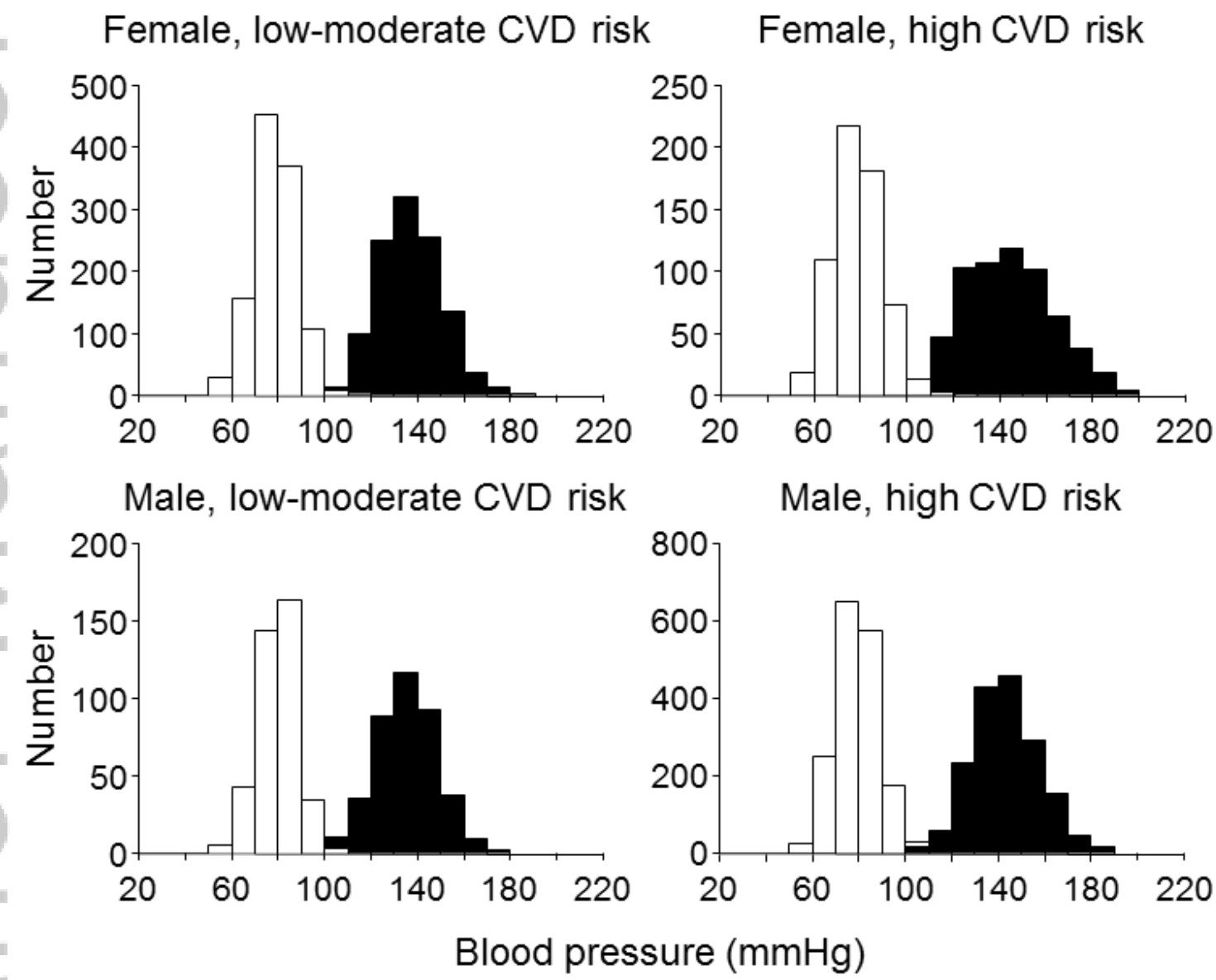

This article is protected by copyright. All rights reserved. 

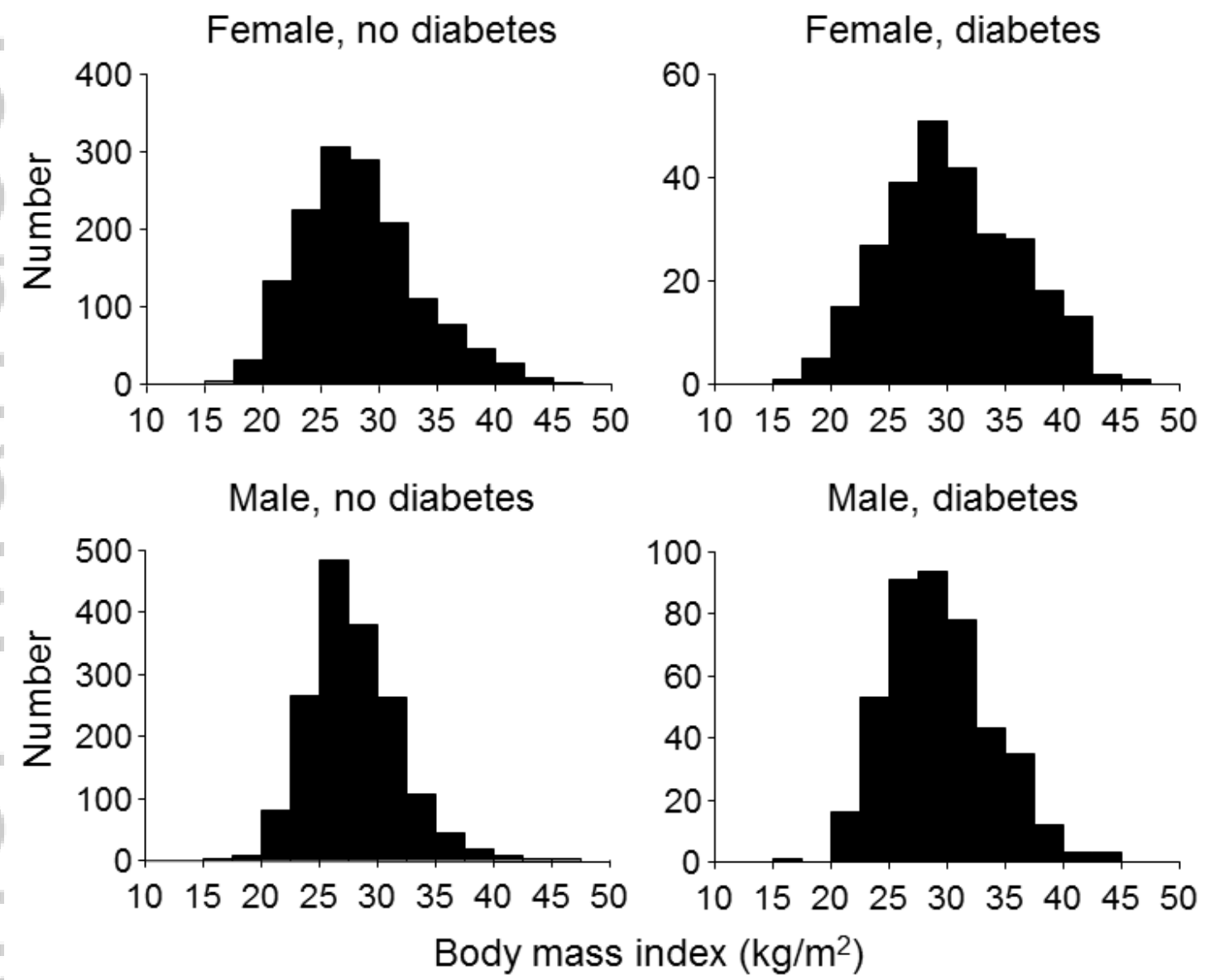

This article is protected by copyright. All rights reserved. 

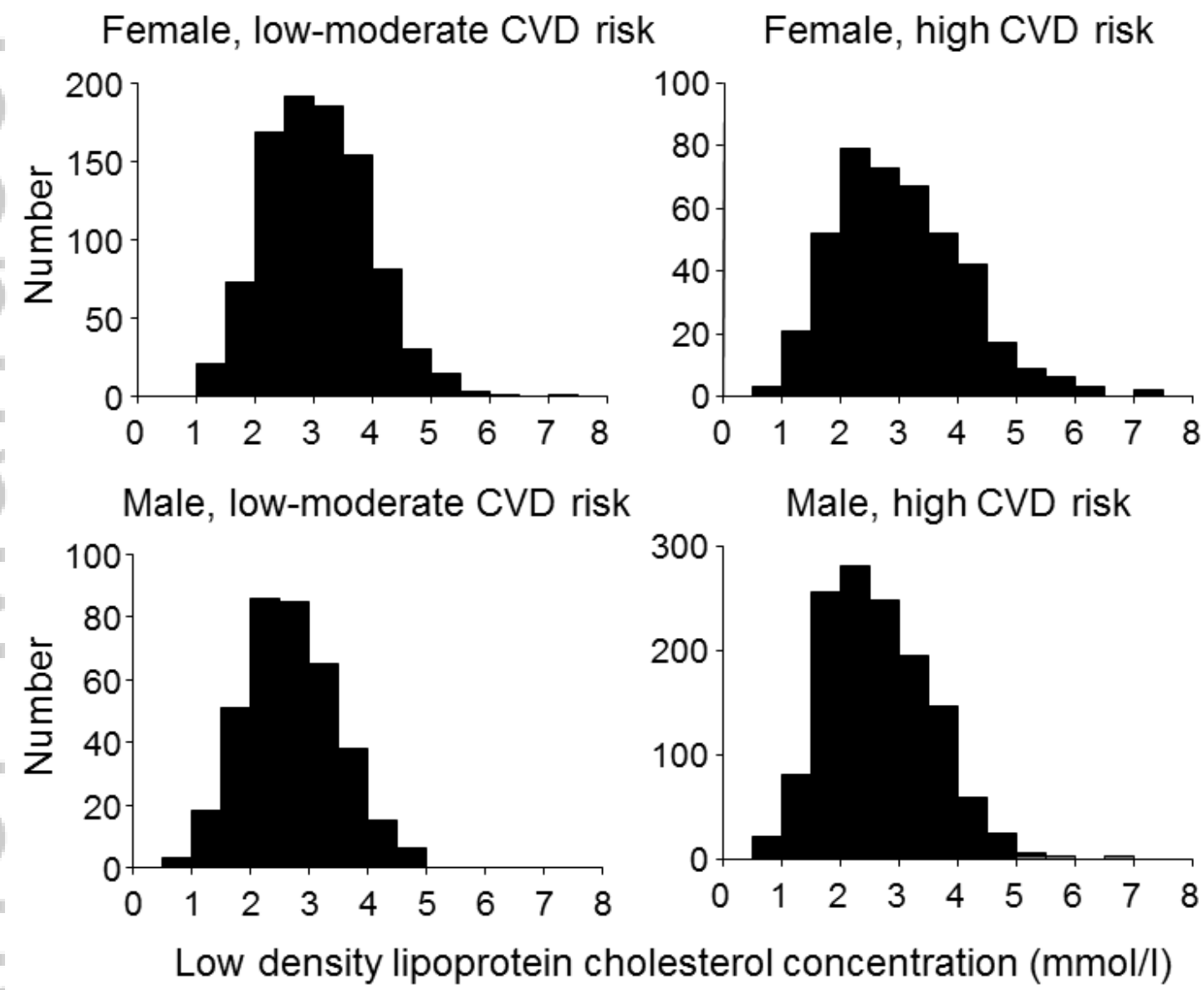

This article is protected by copyright. All rights reserved. 

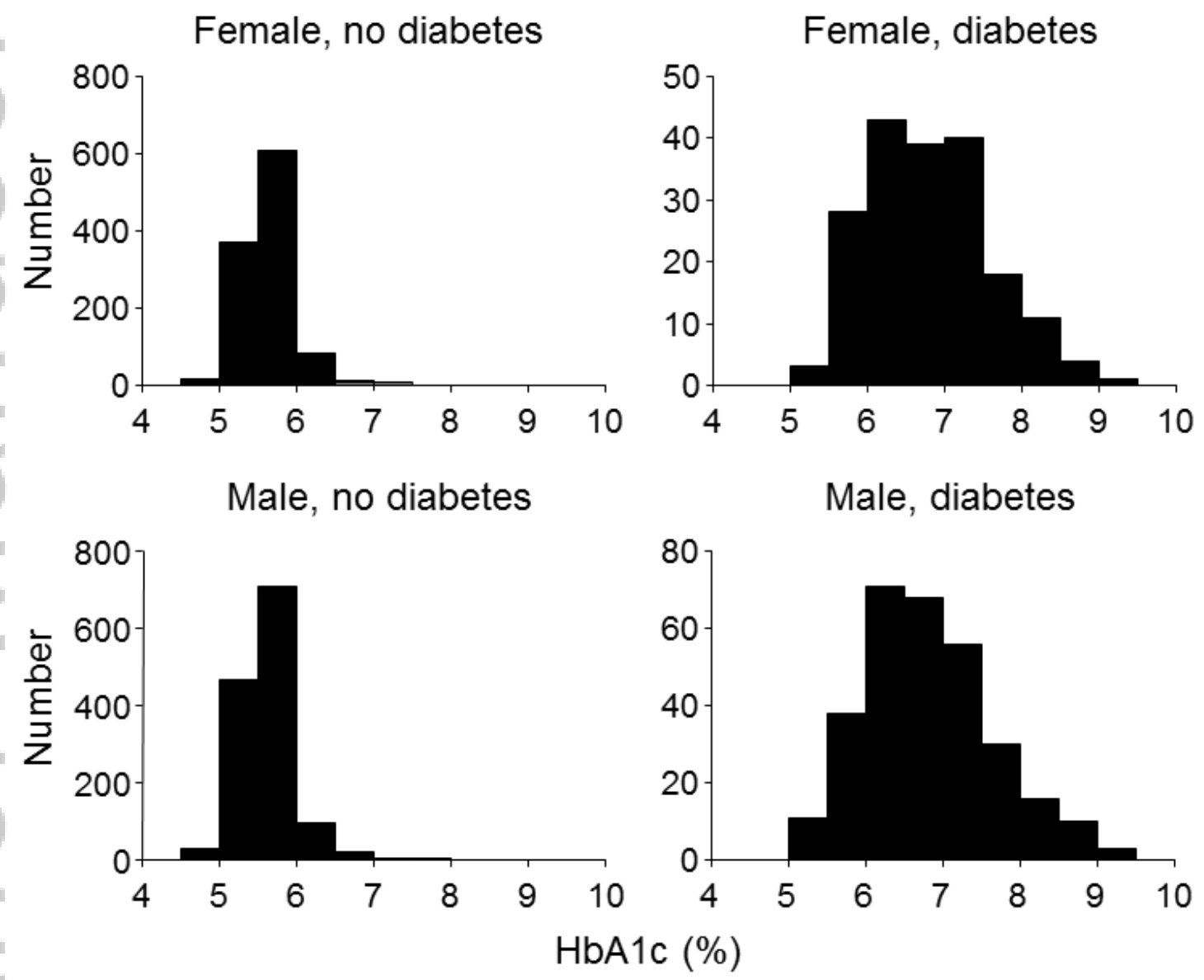

This article is protected by copyright. All rights reserved. 


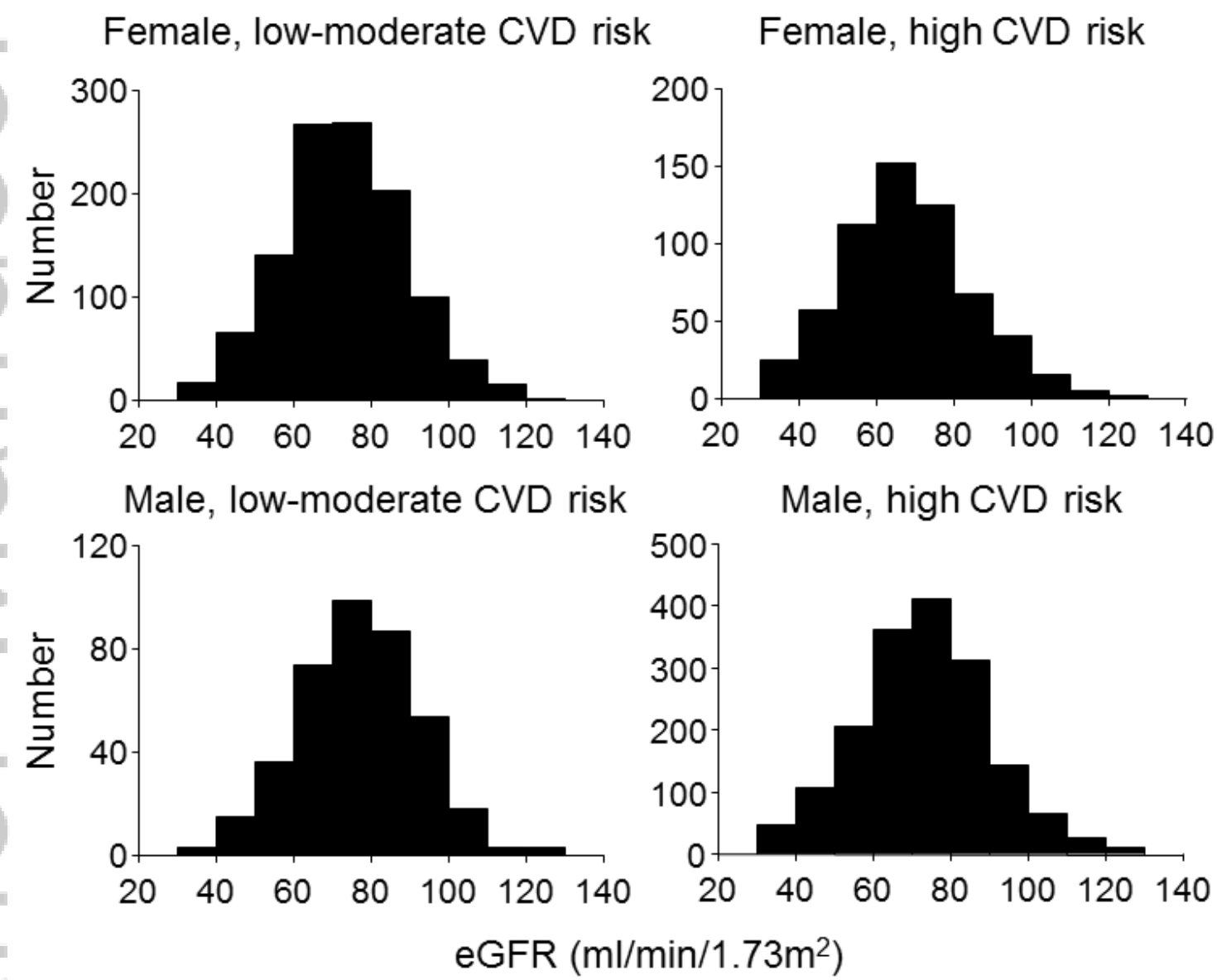

This article is protected by copyright. All rights reserved. 
Risk factor management in a contemporary Australian population at increased cardiovascular disease risk

D. J. Campbell, ${ }^{1,2,3}$ J. M. Coller, ${ }^{3}$ F. F. Gong, ${ }^{1,2,3}$ M. McGrady, ${ }^{4}$ D. L. Prior, ${ }^{2,3}$ U. Boffa, ${ }^{4}$ L. Shiel, ${ }^{4}$ D. Liew, ${ }^{4}$ R. Wolfe, ${ }^{4}$ A. J. Owen, ${ }^{4}$ H. Krum $^{4 *}$ and C. M. Reid $^{4,5}$

${ }^{1}$ St. Vincent's Institute of Medical Research, ${ }^{2}$ University of Melbourne, ${ }^{3}$ St. Vincent's Hospital, Melbourne, ${ }^{4}$ School of Public Health and Preventive Medicine, Monash University, ${ }^{5}$ School of Public Health, Curtin University

*Deceased

Short title: Risk factor management

Correspondence:

Duncan J. Campbell

St. Vincent's Institute of Medical Research

41 Victoria Parade, Fitzroy, Victoria 3065, Australia

Tel: 0392882501

Fax: 0394162676

Email: dcampbell@svi.edu.au

Word count (main text): 3046

This article is protected by copyright. All rights reserved. 


\begin{abstract}
Background: Effective management of cardiovascular and chronic kidney disease risk factors offers longer, healthier lives and savings in health care. We examined risk factor management in participants of the SCReening Evaluation of the Evolution of New Heart Failure (SCREEN-HF) study, a self-selected population at increased cardiovascular disease risk recruited from members of a health insurance fund in Melbourne and Shepparton, Australia.
\end{abstract}

Methods: Inclusion criteria were age e 60 years with one or more of self-reported ischaemic or other heart disease, irregular or rapid heart rhythm, cerebrovascular disease, renal impairment, or treatment for hypertension or diabetes for e 2 years. Exclusion criteria were known heart failure or cardiac abnormality on echocardiography or other imaging. Medical history, clinical examination, full blood examination and biochemistry (without lipids and HbA1c) were performed for 3847 participants on enrolment, and blood pressure, lipids and HbA1c were measured 1-2 years after enrolment for 3202 participants.

Results: Despite 99\% of 3294 participants with hypertension receiving antihypertensive medication, half had blood pressures $>140 / 90 \mathrm{mmHg}$. Approximately $77 \%$ of participants were overweight or obese, with one third obese. Additionally, $74 \%$ of participants at high cardiovascular disease risk had low density lipoprotein cholesterol levels e $2 \mathrm{mmol} / \mathrm{l}$, one third of diabetic participants had $\mathrm{HbA} 1 \mathrm{c}>7 \%, 22 \%$ had estimated glomerular filtration rate $<60 \mathrm{ml} / \mathrm{min} / 1.73 \mathrm{~m}^{2}$, and substantial proportions had under-utilisation of antiplatelet therapy, anticoagulation for atrial fibrillation, and were physically inactive. 
Conclusions: This population demonstrated substantial potential to reduce cardiovascular and renal morbidity and mortality and health care costs through more effective management of modifiable risk factors.

Key words: Risk factors, cardiovascular disease, chronic kidney disease, medication, blood pressure target, population cohort 


\section{Introduction}

Cardiovascular disease (CVD) and chronic kidney disease (CKD) will remain major causes of premature morbidity and mortality and health care costs in Australia for the foreseeable future. Coronary heart and cerebrovascular diseases are the most costly chronic diseases, representing $\sim 22 \%$ of all deaths and $\sim 11 \%$ of years of life lost to ill health, disability or early death, with an annual cost of $\$ 7.74$ billion ( $\sim 10.4 \%$ of total health expenditure) due to CVD in Australia in 2008-2009. ${ }^{1}$ Despite substantial reductions in age-standardised rates for fatal and non-fatal CVD, population increases have resulted in little change or a rise in the numbers of years lost due to death and disability from CVD between 2003-2011 in Australia. ${ }^{2}$ Moreover, CKD contributes to $>10 \%$ of all deaths in Australia, ${ }^{1}$ and agestandardised rates for non-fatal CKD increased during 2003-2011, together with substantial increases in the numbers of years lost due to death and disability from CKD. ${ }^{2}$

CVD and CKD risk factors are so called because they predict premature cardiovascular and renal morbidity and mortality. ${ }^{3,4}$ Elevated blood pressure (BP), physical inactivity, elevated body mass index (BMI), elevated cholesterol, tobacco use, low intake of fruit and vegetables, alcohol use and diabetes are major risk factors for CVD. ${ }^{2}$ Elevated BP, elevated BMI and diabetes are also major risk factors for $\mathrm{CKD},{ }^{2}$ and $\mathrm{CKD}$ is a risk factor for $\mathrm{CVD} .{ }^{5}$ Individuals without CVD risk factors live longer, healthier lives and the resultant compression of morbidity offers substantial savings in health care costs. ${ }^{4,6}$ Many studies show that risk factor modification prevents and postpones CVD and CKD, and is cost-effective. ${ }^{7-13}$

The SCReening Evaluation of the Evolution of New Heart Failure (SCREEN-HF) study is a community-based evaluation of the use of plasma amino-terminal-pro-B-type natriuretic peptide (NT-proBNP) to identify individuals with cardiac dysfunction (as assessed by 
echocardiography) and increased risk of heart failure and other cardiovascular events.

SCREEN-HF study participants were volunteers aged e 60 years with self-reported CVD risk factors who were predominantly privately insured. We examined the CVD and CKD risk factors for SCREEN-HF participants to assess the potential for reduction in cardiovascular and renal morbidity and mortality and health care costs through more effective management of modifiable risk factors. 


\section{Methods}

\section{Study population}

Letters of invitation and a questionnaire were sent to 44000 members of a health insurance fund (Bupa Australia Pty Ltd) aged e 60 years who lived in Melbourne or Shepparton, Victoria, although we also recruited non-Bupa members. There were 11126 returned questionnaires and 9560 consecutive respondents were screened by phone until 4054 participants were enrolled. Baseline study visits (visit 1) were conducted at Dorevitch Pathology collection centres where a study nurse obtained consent from, interviewed and examined the participant and collected a non-fasting blood sample for measurement of electrolytes, creatinine, urea, glucose, full blood examination and NT-proBNP. Lipids and HbAlc were not measured at visit 1 . Of 4054 individuals attending the baseline study visit, 3847 met the inclusion and exclusion criteria, 3706 from metropolitan Melbourne and 141 from Shepparton. Of the 3847 participants, 3658 (92\%) were Bupa members. Inclusion criteria were age e 60 years with one or more of self-reported myocardial infarction or other ischaemic or valvular heart disease, irregular or rapid heart rhythm, cerebrovascular disease, renal impairment, or treatment for hypertension or diabetes for e 2 years. Exclusion criteria were previously diagnosed heart failure or cardiac abnormality on previous echocardiography or other cardiac imaging; these exclusions included previous valve surgery and previously documented valve abnormality graded $>$ mild. Recruitment commenced in May 2007 and was completed in January 2010. Participants were invited to attend for a second visit (visit 2), a median of 483 (interquartile range 200-704) days following visit 1, at which BP was measured, interim events recorded, blood was taken and plasma, serum and red cells stored at $-80^{\circ} \mathrm{C}$, and echocardiography performed. Lipids and $\mathrm{HbA} 1 \mathrm{c}$ were measured on frozen serum and red cells, respectively. A flow chart describing the recruitment strategy is shown in

Figure 1. The participant numbers include a greater number of excluded participants than our 
previous report where exclusion criteria were based on self-report alone. ${ }^{14}$ Subsequent collection of additional clinical information from chart review and requests for information from hospitals and clinicians resulted in an additional 150 participants being excluded from the current analysis.

\section{Study variables}

\section{Blood pressure}

BP was measured with the participant in a seated position after at least 5 minutes rest. An appropriate cuff size was used, the arm was supported by a table at heart level, and the BP measured with an automatic BP monitor (A\&D Medical, Kensington, Victoria). Two readings were taken 3 minutes apart and recorded. In the present analysis we used the mean of these 2 readings from each visit.

\section{Clinical factors}

Height, weight and waist circumference were measured at interview, and age, sex, and past medical history recorded, which included ischaemic heart disease (myocardial infarction, angina, coronary revascularisation), valvular or other heart disease or heart surgery, hypertension, respiratory disease, renal impairment, cardiac arrhythmia including atrial fibrillation (AF), cerebrovascular disease, diabetes, peripheral vascular disease (including aortic and carotid disease), obstructive sleep apnoea, and pacemaker use. Self-reported details of lifestyle factors included exercise, smoking history, and alcohol intake. Participants brought details of their medications to the baseline study visit, which were recorded. All blood tests except HbA1c were performed by Dorevitch Pathology (Heidelberg, Victoria) and estimated glomerular filtration rate (eGFR) was calculated using the Modification of Diet in Renal Disease study equation. ${ }^{15}$ Plasma NT-proBNP was measured by 
electrochemiluminescence immunoassay using an Elecsys instrument (Roche Diagnostics, Basel, Switzerland) with a lower limit of detection of $0.6 \mathrm{pmol} / 1$. HbAlc was measured by high performance liquid chromatography on first-thaw frozen red cells by St. Vincent's Pathology, Melbourne, using an Akray Adams HA-8160 HbA1c analyser. Absolute 5-year CVD risk was calculated as half of the 10-year risk estimated using the Framingham risk prediction model based on sex, age, total and high-density lipoprotein cholesterol, systolic BP (SBP), treatment for hypertension, smoking, and diabetes status; for participants without lipid measurement, the alternate algorithm based on sex, age, BMI, SBP, antihypertensive medication use, current smoking, and diabetes status was used. ${ }^{16}$ Each participant was provided with documentation of their blood test results and blood pressure, height and weight, with the suggestion that they provide the information to their primary care physician.

\section{Ethics approval and study registration}

The SCREEN-HF study was approved by the Alfred Human Research Ethics Committee and written informed consent was obtained from all participants. The study was registered at ClinicalTrials.gov NCT00400257, NCT00604006, and NCT01581827.

\section{Statistical analysis}

Analyses were conducted using Statview 5.0.1 (SAS Institute, Cary, NC, USA), except for intra-class correlation (ICC) calculations using SPSS (IBM Corp. Armonk, NY). Summary statistics were percentages for categorical variables and medians with 25 th and 75 th percentiles for continuous variables. Differences between groups were tested with $\chi^{2}$ tests for categorical variables and statistical significance was interpreted as a 2 -tailed $P$ value $<0.05$. 


\section{Results}

\section{CVD risk}

Participant characteristics are summarised in Tables 1 and 2. All participants had at least one CVD risk factor on enrolment, with 60\% having high CVD risk (Framingham 5-year risk score $>15 \%$ or known CVD). High CVD risk was more prevalent in men (81\%) than in women $(35 \%)$ (Table 1$)$.

\section{Blood pressure}

Median BPs for visits $1(139 / 81 \mathrm{mmHg})$ and $2(139 / 76 \mathrm{mmHg})$ were similar, with a median BP difference $\left(25^{\text {th }}\right.$ percentile to $75^{\text {th }}$ percentile $)$ of $-0(-12$ to +11$) /-4(-12$ to +3$) \mathrm{mmHg}$ for the 3200 participants with BP measured at both visits. The ICCs were 0.599 and 0.605 for SBP and DBP, respectively, with $66 \%$ agreement between visits 1 and 2 with respect to SBP above or below a threshold of $140 \mathrm{mmHg}$. Given that averaging BP measurements from two visits improves predictiveness of this risk factor, ${ }^{17}$ mean BP for visits 1 and 2 was calculated for the 3200 participants with BP measured at both visits, whereas mean BP from visit 1 was calculated for the remainder.

Of the 3847 participants, 3294 (86\%) were known to have hypertension on enrolment, of whom 3271 (99\%) were receiving antihypertensive medication. Despite this treatment, 45\% of women and $52 \%$ of men had SBP above the recommended target of $140 \mathrm{mmHg} .{ }^{18} \mathrm{~A}$ higher proportion of participants with high CVD risk (Framingham 5-year risk score $>15 \%$ or known CVD) had SBP >140 mmHg than participants with low or moderate CVD risk (women: $56 \%$ vs. $38 \%, \mathrm{P}<0.0001$; men: $56 \%$ vs. $35 \%, \mathrm{P}<0.0001$ ) (Figure 2). Moreover, $90 \%$ 
of women and 94\% of men in the SCREEN-HF study had an SBP above a target SBP $<120$ mmHg proposed by recent Australian guidelines for selected high CVD risk populations. ${ }^{19}$

\section{BMI and waist circumference}

The majority of participants were overweight, with 1300 (75\%) women and $1672(80 \%)$ men with BMI $>25 \mathrm{~kg} / \mathrm{m}^{2}$, and $615(35 \%)$ women and $623(30 \%)$ men with BMI $>30 \mathrm{~kg} / \mathrm{m}^{2}$ (Figure 3). Moreover, $90 \%$ of women had a waist circumference e $80 \mathrm{~cm}$ and $83 \%$ of men had a waist circumference e $94 \mathrm{~cm}$, whereas $29 \%$ of women had a waist circumference e 88 $\mathrm{cm}$ and $44 \%$ of men had a waist circumference e $102 \mathrm{~cm} \cdot{ }^{20}$ Higher percentages of diabetic than non-diabetic women and men had BMI $>30 \mathrm{~kg} / \mathrm{m}^{2}$ (women: $49 \%$ vs. $33 \%, \mathrm{P}<0.0001$; men: $41 \%$ vs. $27 \%, \mathrm{P}<0.0001$ ) (Figure 3).

\section{Cholesterol}

For participants without known CVD and Framingham 5-year risk score d15\%, 32\% of women and $19 \%$ of men had low density lipoprotein (LDL) cholesterol levels $>3.4 \mathrm{mmol} / \mathrm{l}$, the definition of dyslipidaemia in recent guidelines of the US Preventive Services Task Force $^{21}$ (Figure 4). Moreover, $81 \%$ of women and $72 \%$ of men with high CVD risk (Framingham 5-year risk score $>15 \%$ or known CVD) had serum LDL cholesterol levels above the target of $<2 \mathrm{mmol} / \mathrm{l}$ recommended in recent guidelines. ${ }^{18}$ For participants with previous myocardial infarction, $78 \%$ of women and $68 \%$ of men had serum LDL cholesterol levels above the target of $<1.8 \mathrm{mmol} / 1$ recommended by the National Heart Foundation of Australia and the Cardiac Society of Australia and New Zealand. ${ }^{22}$

\section{$\mathrm{HbAlc}$}

This article is protected by copyright. All rights reserved. 
Using an HbA1c threshold of $6.5 \%,{ }^{23} 1.5 \%$ of women and $2.3 \%$ of men had undiagnosed diabetes, and $0.5 \%$ of women and $0.7 \%$ of men with undiagnosed diabetes had an $\mathrm{HbA} 1 \mathrm{c}$ $>7 \%$. By contrast, $32 \%$ of diabetic women and $35 \%$ of diabetic men had an $\mathrm{HbA} 1 \mathrm{c}$ above the recommended target of $\mathrm{d} 7 \%,{ }^{24}$ and $8 \%$ of diabetic women and $9 \%$ of diabetic men had an HbA1c $>8 \%$ (Figure 5).

\section{eGFR}

Reduced eGFR $\left(<60 \mathrm{ml} / \mathrm{min} / 1.73 \mathrm{~m}^{2}\right)$ was present in $436(25 \%)$ women and $426(20 \%)$ men. Reduced eGFR was more prevalent in participants at high CVD risk (Framingham 5-year risk score $>15 \%$ or known CVD) than those without (women: $33 \%$ vs. $20 \%, \mathrm{P}<0.0001$; men: $22 \%$ vs. $14 \%, \mathrm{P}=0.0003$ ) (Figure 6).

\section{Vascular disease, and statin and anti-platelet therapy}

Of the 1209 participants with CVD (coronary, cerebrovascular and/or peripheral), $34 \%$ of women and $20 \%$ of men were not receiving statin therapy, $30 \%$ of women and $21 \%$ of men were not receiving aspirin or clopidogrel therapy, and $15 \%$ of women and $7 \%$ of men were not receiving either statin or antiplatelet therapy. Of 1777 participants with high CVD risk (Framingham 5-year risk score $>15 \%$ or known CVD) who had serum LDL cholesterol levels measured, $57 \%$ of women and $57 \%$ of men were receiving statin therapy, but $71 \%$ of women and $58 \%$ of men with high CVD risk receiving statin therapy had serum LDL cholesterol levels e $2 \mathrm{mmol} / \mathrm{l}$.

\section{Atrial fibrillation, $\mathrm{CHA}_{2} \mathrm{DS}_{2}-\mathrm{VASc}$ score and anticoagulant therapy}

SCREEN-HF recruitment was complete before approval of novel oral anticoagulants by the Therapeutic Goods Administration. Of the 393 participants with AF, 60 (15\%) had had a 
previous stroke and/or transient ischaemic attack (TIA); 147 (97\%) women and 172 (71\%) men with AF had a $\mathrm{CHA}_{2} \mathrm{DS}_{2}$-VASc score e $2,{ }^{25}$ but $69 \%$ of women and $59 \%$ of men with $\mathrm{AF}$ and a $\mathrm{CHA}_{2} \mathrm{DS}_{2}$-VASc score e 2 were not receiving warfarin therapy, and $27 \%$ of women and $23 \%$ of men with $\mathrm{AF}$ and a $\mathrm{CHA}_{2} \mathrm{DS}_{2}$-VASc score e 2 were not receiving either warfarin or antiplatelet therapy.

\section{Physical activity}

Of the 3186 participants who completed the exercise questionnaire, 1055 (33\%) stated they walked for, on average, e 30 minutes per day and/or participated in, on average, e 10 minutes per day of more vigorous exercise, including housework. 


\section{Discussion}

The high prevalence of uncontrolled risk factors in SCREEN-HF participants demonstrates substantial potential for reduction in CVD and CKD morbidity and mortality and compression of morbidity through improved risk factor management. A similar potential for substantial health gains from improved management of CVD risk was reported for a cross sectional representative cohort that participated in the 2011-2012 Australian National Health Measures Survey, where it was noted that most individuals with high absolute CVD risk were not receiving currently recommended BP and lipid lowering therapies. ${ }^{26}$ Our data for SCREEN-HF participants add to previous reports by providing information on a broad spectrum of risk factors in a community population at increased CVD risk, all of whom had general practitioners and were largely receiving appropriate therapies. Yet, despite appropriate therapies, approximately half of SCREEN-HF participants had BP e 140/90 and $74 \%$ of participants at high CVD risk had serum LDL cholesterol levels above a target of $<2$ $\mathrm{mmol} / \mathrm{l}$. In addition, we found a high prevalence of overweight and obesity, a third of diabetic participants had $\mathrm{HbA} 1 \mathrm{c}$ levels above target, and there was under-utilisation of antiplatelet therapy in participants with vascular disease, and anticoagulant therapy in participants with AF. At least two thirds of participants failed to meet recommended physical activity targets, ${ }^{27}$ and CKD was present in $22 \%$ of participants.

We previously reported therapeutic inertia for BP management of SCREEN-HF participants, ${ }^{14}$ who achieved a level of BP control no better than that reported for the general Australian community, ${ }^{28,29}$ and the present report documents a similar inertia for cholesterol management. Our choice of BP $<140 / 90 \mathrm{mmHg}$ as a measure of BP control was to allow comparison with previous Australian studies, ${ }^{28,29}$ and a target $\mathrm{SBP}<120 \mathrm{mmHg}$ has been proposed for selected high CVD risk populations without diabetes. ${ }^{19}$ Although a target of 
$<130 / 80 \mathrm{mmHg}$ has been recommended for individuals with diabetes or micro or macroalbuminuria, ${ }^{18}$ the appropriateness of a BP target lower than $<140 / 90$ in diabetic patients is the subject of debate. ${ }^{30}$ There is also uncertainty about the appropriateness of a BP target lower than $<140 / 90$ in patients with CKD. ${ }^{31,32}$ The third of diabetic participants with HbA1c levels above target, and under-utilisation of antiplatelet therapies in participants with vascular disease and anticoagulant therapy in participants with AF also demonstrate therapeutic inertia.

The Systolic Blood Pressure Intervention Trial (SPRINT) showed that a mean SBP of 121 $\mathrm{mmHg}$ could be achieved with a mean of $2.8 \mathrm{BP}$ medications in individuals at increased CVD risk. ${ }^{9}$ It is therefore likely that improved risk factor control through titration of therapies could be achieved with little additional cost. Participants brought details of their medications to the baseline study visit, and it is reasonable to assume that they were largely compliant with the medications they reported and that they would be similarly compliant with any titration of therapy, particularly if they understood why their medication was being titrated. The benefits of risk factor control are well established and cost effective, ${ }^{7-13}$ enable individuals with risk factors to live longer, healthier lives, and the resultant compression of morbidity offers substantial savings in health care costs. ${ }^{4,6}$

Although age is a key non-modifiable risk factor, the benefits of risk factor management extend to older age as risk factor modification produces greater absolute risk reduction as baseline risk increases with age. ${ }^{33}$ The benefits of BP lowering were similar for individuals older and younger than 75 years in the SPRINT study, ${ }^{34}$ and the benefits of statin therapy were similar for individuals older and younger than 65 years in the Heart Outcomes Prevention Evaluation (HOPE)-3 study. ${ }^{11}$ 
There have been many proposed strategies to improve risk factor management. In addition to therapeutic inertia, failure to meet BP targets has been attributed to underuse of combination therapies and undetected non-adherence, together with failure to inform clinicians of the likely need for treatment intensification and the advantages of adding an additional BP drug instead of up-titrating existing therapy. ${ }^{35}$ Other strategies that may improve risk factor control include pay-for-performance incentive, ${ }^{36}$ pharmacist intervention, ${ }^{37}$ telephone support, ${ }^{38}$ and point-of-care electronic decision support with audit and feedback tools. ${ }^{39}$

Overweight and obesity contribute to the burden of CVD, diabetes and CKD. ${ }^{2}$ The Australian Institute of Health and Welfare estimates that $6 \%$ of future disease burden in 2020 due to overweight and obesity could be avoided if current increases in overweight and obesity were halted (maintained at 2011 levels). ${ }^{40}$ Furthermore, $14 \%$ of disease burden due to overweight and obesity in the year 2020 could be avoided if the population at risk in 2011 reduced their BMI by $1 \mathrm{~kg} / \mathrm{m}^{2}$ and these rates were maintained in 2020, compared with what would be the case if overweight and obesity continued to rise. ${ }^{40}$ The lower body weight and diabetes incidence produced by lifestyle intervention with low-calorie diet and moderate physical activity during the 2.8-year duration of the Diabetes Prevention Program Outcomes Study persisted for the next 7 years. ${ }^{41,42}$ There is, however, need to avoid rebound weight gain because body weight fluctuations may increase the risk of cardiovascular events in patients with coronary disease. ${ }^{43}$ Whereas therapeutic inertia may be an important contributor to the failure to adequately control elevated BP and LDL cholesterol levels, and HbA1c levels in diabetic patients, environmental parameters may offer an alternative strategy to reduce BMI and diabetes. $^{44,45}$ 
There are several limitations to our study. SCREEN-HF study participants were not a representative sample of Australians e 60 years of age. They were self-selected with selfreported CVD risk factors living in Melbourne or Shepparton, and 61\% had high CVD risk. Some SCREEN-HF participants may have been "worried well" and adopted behaviours designed to protect them from CVD, whereas others may have volunteered because they are at increased risk. At the least, our study provides information about a group of individuals who were motivated to participate in health research. All had general practitioners and at least $92 \%$ had sufficient income to afford private health insurance. Our data can therefore be interpreted as a "best-case" scenario for risk factor control in Australians at increased CVD risk. Although approximately 10 years have elapsed since SCREEN-HF enrolment began, other reports suggest little change in risk factor management over that time. ${ }^{26}$

\section{Conclusion}

Our comprehensive description of risk factors for a community population at increased CVD risk demonstrated substantial potential to reduce cardiovascular and renal morbidity and mortality and health care costs through more effective management of modifiable risk factors.

This article is protected by copyright. All rights reserved. 


\section{Acknowledgements}

The SCREEN-HF study was initially funded by Bupa Australia, with subsequent support from the National Health and Medical Research Council (NHMRC) of Australia, the National Heart Foundation of Australia and the Diabetes Australia Research Trust. Duncan Campbell received a senior research fellowship from the NHMRC, and Michele McGrady and Jennifer Coller received scholarship support from the NHMRC. St Vincent's Institute of Medical Research is supported in part by the Victorian Government's Operational Infrastructure Support Program. We are very grateful to Bupa Australia and to Sonia Danielewski for their contribution to study recruitment, and to Dorevitch Pathology. We thank all SCREEN-HF study participants and the study nurses and administrative staff for their invaluable contribution.

\section{Competing interests}

Bupa Australia was involved in study design, recruitment of participants, and funding, but was not involved in data collection, analysis or interpretation, or writing of the article. Bupa Australia had no control or influence over the decision to submit the final manuscript for publication.

Duncan Campbell has received payments from the Australasian Renin Academy for lectures. David Prior has received payment from Servier for sitting on their advisory board, and from Boehringer Ingleheim, CSL, Merck Sharp \& Dohme and Sanofi Aventis for lectures. Umberto Boffa was an employee of Bupa Australia. Danny Liew has received honoraria from Pfizer, Sanofi, Astra-Zeneca, Abbott, Bayer, MSD, GSK, Novartis and Nycomed. Henry Krum has received support from Novartis, Bristol-Myers Squibb, and Ardian/Medtronic. 


\section{References}

1 Australian Institute of Health and Welfare. Australia's health 2014. Canberra: AIHW 2014.

2 Australian Institute of Health and Welfare. Australian Burden of Disease Study: Impact and causes of illness and death in Australia 2011. Canberra: AIHW 2016.

3 Lloyd-Jones DM, Leip EP, Larson MG, D'Agostino RB, Beiser A, Wilson PW, et al. Prediction of lifetime risk for cardiovascular disease by risk factor burden at 50 years of age. Circulation. 2006; 113: 791-8.

4 Allen NB, Zhao L, Liu L, Daviglus M, Liu K, Fries J, et al. Favorable cardiovascular health, compression of morbidity, and healthcare costs: forty-year follow-up of the CHA Study (Chicago Heart Association Detection Project in Industry). Circulation. 2017; 135: 1693-701.

5 Gansevoort RT, Correa-Rotter R, Hemmelgarn BR, Jafar TH, Heerspink HJ, Mann $\mathrm{JF}$, et al. Chronic kidney disease and cardiovascular risk: epidemiology, mechanisms, and prevention. Lancet. 2013; 382: 339-52.

6 Fries JF. Frailty, heart disease, and stroke: the Compression of Morbidity paradigm. Am J Prev Med. 2005; 29: 164-8.

7 Ravera M, Re M, Deferrari L, Vettoretti S, Deferrari G. Importance of blood pressure control in chronic kidney disease. J Am Soc Nephrol. 2006; 17: S98-103.

8 Ettehad D, Emdin CA, Kiran A, Anderson SG, Callender T, Emberson J, et al. Blood pressure lowering for prevention of cardiovascular disease and death: a systematic review and meta-analysis. Lancet. 2016; 387: 957-67.

9 The Sprint Research Group. A randomized trial of intensive versus standard bloodpressure control. N Engl J Med. 2015; 373: 2103-16.

10 Taylor F, Huffman MD, Macedo AF, Moore TH, Burke M, Davey Smith G, et al. Statins for the primary prevention of cardiovascular disease. Cochrane Database Syst Rev. 2013; 1: CD004816.

11 Yusuf S, Bosch J, Dagenais G, Zhu J, Xavier D, Liu L, et al. Cholesterol lowering in intermediate-risk persons without cardiovascular disease. $N$ Engl J Med. 2016; 374: 2021-31.

12 Pandya A, Sy S, Cho S, Weinstein MC, Gaziano TA. Cost-effectiveness of 10-Year risk thresholds for initiation of statin therapy for primary prevention of cardiovascular disease. JAMA. 2015; 314: 142-50.

13 Richman IB, Fairley M, Jorgensen ME, Schuler A, Owens DK, Goldhaber-Fiebert JD. Cost-effectiveness of intensive blood pressure management. JAMA Cardiol. 2016; 1: 872-79.

14 Campbell DJ, McGrady M, Prior DL, Coller JM, Boffa U, Shiel L, et al. Most individuals with treated blood pressures above target receive only one or two antihypertensive drug classes. Intern Med J. 2013; 43: 137-43.

15 Levey AS, Bosch JP, Lewis JB, Greene T, Rogers N, Roth D. A more accurate method to estimate glomerular filtration rate from serum creatinine: a new prediction equation. Modification of Diet in Renal Disease Study Group. Ann Intern Med. 1999; 130: 461-70.

16 D'Agostino RB, Sr., Vasan RS, Pencina MJ, Wolf PA, Cobain M, Massaro JM, et al. General cardiovascular risk profile for use in primary care: the Framingham Heart Study. Circulation. 2008; 117: 743-53.

17 Bell K, Hayen A, McGeechan K, Neal B, Irwig L. Effects of additional blood pressure and lipid measurements on the prediction of cardiovascular risk. Eur J Prev Cardiol. 2012; 19: 1474-85.

18 National Vascular Disease Prevention Alliance. Guidelines for the management of absolute cardiovascular disease risk. National Stroke Foundation. Available at: 
http://www.heartfoundation.org.au/information-for-professionals/ClinicalInformation/Pages/absolute-risk.aspx. Accessed May 27, 2017).

19 Gabb GM, Mangoni AA, Anderson CS, Cowley D, Dowden JS, Golledge J, et al. Guideline for the diagnosis and management of hypertension in adults - 2016. Med J Aust. 2016; 205: 85-9.

20 Lean ME, Han TS, Morrison CE. Waist circumference as a measure for indicating need for weight management. BMJ. 1995; 311: 158-61.

21 U. S. Preventive Services Task Force. Statin Use for the Primary Prevention of Cardiovascular Disease in Adults: US Preventive Services Task Force Recommendation Statement. JAMA. 2016; 316: 1997-2007.

22 National Heart Foundation of Australia and The Cardiac Society of Australia and New Zealand. Reducing risk in heart disease: an expert guide to clinical practice for secondary prevention of coronary heart disease. Melbourne: National Heart Foundation of Australia 2012.

23 d'Emden MC, Shaw JE, Colman PG, Colagiuri S, Twigg SM, Jones GR, et al. The role of $\mathrm{HbAlc}$ in the diagnosis of diabetes mellitus in Australia. Med J Aust. 2012; 197: 2201.

24 Gunton JE, Cheung NW, Davis TM, Zoungas S, Colagiuri S, Australian Diabetes S. A new blood glucose management algorithm for type 2 diabetes: a position statement of the Australian Diabetes Society. Med J Aust. 2014; 201: 650-3.

25 Lip GY, Nieuwlaat R, Pisters R, Lane DA, Crijns HJ. Refining clinical risk stratification for predicting stroke and thromboembolism in atrial fibrillation using a novel risk factor-based approach: the euro heart survey on atrial fibrillation. Chest. 2010; 137: 26372 .

26 Banks E, Crouch SR, Korda RJ, Stavreski B, Page K, Thurber KA, et al. Absolute risk of cardiovascular disease events, and blood pressure- and lipid-lowering therapy in Australia. Med J Aust. 2016; 204: 320.e1-20.e8.

27 Department of Health. More than half of all Australian adults are not active enough. Commonwealth of Australia. Available at:

http://www.health.gov.au/internet/main/publishing.nsf/content/F01F92328EDADA5BCA257 BF0001E720D/\$File/10141 PA Guidelines_A5_18-64yrs FINAL (D14-964586).PDF. Accessed September 28, 2017.

28 Briganti EM, Shaw JE, Chadban SJ, Zimmet PZ, Welborn TA, McNeil JJ, et al. Untreated hypertension among Australian adults: the 1999-2000 Australian Diabetes, Obesity and Lifestyle Study (AusDiab). Med J Aust. 2003; 179: 135-9.

29 Carrington MJ, Jennings GL, Stewart S. Pattern of blood pressure in Australian adults: results from a national blood pressure screening day of 13,825 adults. Int J Cardiol. 2010; 145: 461-7.

30 Brunstrom M, Carlberg B. Effect of antihypertensive treatment at different blood pressure levels in patients with diabetes mellitus: systematic review and meta-analyses. $B M J$. 2016; 352: i717.

31 Xie X, Atkins E, Lv J, Bennett A, Neal B, Ninomiya T, et al. Effects of intensive blood pressure lowering on cardiovascular and renal outcomes: updated systematic review and meta-analysis. Lancet. 2016; 387: 435-43.

32 Tsai WC, Wu HY, Peng YS, Yang JY, Chen HY, Chiu YL, et al. Association of Intensive Blood Pressure Control and Kidney Disease Progression in Nondiabetic Patients With Chronic Kidney Disease: A Systematic Review and Meta-analysis. JAMA Intern Med. 2017; 177: 792-99. 
33 Blood Pressure Lowering Treatment Trialists C, Sundstrom J, Arima H, Woodward M, Jackson R, Karmali K, et al. Blood pressure-lowering treatment based on cardiovascular risk: a meta-analysis of individual patient data. Lancet. 2014; 384: 591-8.

34 Williamson JD, Supiano MA, Applegate WB, Berlowitz DR, Campbell RC, Chertow $\mathrm{GM}$, et al. Intensive vs standard blood pressure control and cardiovascular disease outcomes in adults aged e 75 Years: a randomized clinical trial. JAMA. 2016; 315: 2673-82.

35 Atkins ER, Rodgers A. Redefining blood pressure targets. Are there better criteria for assessing high blood pressure than pressure measurements. Eur Heart J. 2017; 38: 1008-16.

36 Cupples ME, Byrne MC, Smith SM, Leathem CS, Murphy AW. Secondary

prevention of cardiovascular disease in different primary healthcare systems with and without pay-for-performance. Heart. 2008; 94: 1594-600.

37 Santschi V, Chiolero A, Colosimo AL, Platt RW, Taffe P, Burnier M, et al. Improving blood pressure control through pharmacist interventions: a meta-analysis of randomized controlled trials. $J$ Am Heart Assoc. 2014; 3: e000718.

38 Vale MJ, Jelinek MV, Best JD, Dart AM, Grigg LE, Hare DL, et al. Coaching patients On Achieving Cardiovascular Health $(\mathrm{COACH})$ : a multicenter randomized trial in patients with coronary heart disease. Arch Intern Med. 2003; 163: 2775-83.

39 Chalasani S, Peiris DP, Usherwood T, Redfern J, Neal BC, Sullivan DR, et al. Reducing cardiovascular disease risk in diabetes: a randomised controlled trial of a quality improvement initiative. Med J Aust. 2017; 206: 436-41.

40 Australian Institute of Health and Welfare. Impact of overweight and obesity as a risk factor for chronic conditions: Australian Burden of Disease Study. Canberra: AIHW 2017. 41 Diabetes Prevention Program Research Group. Reduction in the incidence of type 2 diabetes with lifestyle intervention or metformin. N Engl J Med. 2002; 346: 393-403.

42 Diabetes Prevention Program Research Group, Knowler WC, Fowler SE, Hamman RF, Christophi CA, Hoffman HJ, et al. 10-year follow-up of diabetes incidence and weight loss in the Diabetes Prevention Program Outcomes Study. Lancet. 2009; 374: 1677-86.

43 Bangalore S, Fayyad R, Laskey R, DeMicco DA, Messerli FH, Waters DD. Bodyweight fluctuations and outcomes in coronary disease. $N$ Engl J Med. 2017; 376: 1332-40.

44 Creatore MI, Glazier RH, Moineddin R, Fazli GS, Johns A, Gozdyra P, et al. Association of neighborhood walkability with change in overweight, obesity, and diabetes. JAMA. 2016; 315: 2211-20.

45 Celis-Morales CA, Lyall DM, Welsh P, Anderson J, Steell L, Guo Y, et al. Association between active commuting and incident cardiovascular disease, cancer, and mortality: prospective cohort study. BMJ. 2017; 357: j1456.

46 National Health and Medical Research Council of Australia. Australian guidelines to reduce health risks from drinking alcohol. Canberra: Australian Government 2009. 


\section{Legend to figure}

Figure 1. Flow chart of numbers of individuals invited to participate in the SCReening Evaluation of the Evolution of New Heart Failure study who were subsequently enrolled and attended visits 1 and 2. NT-proBNP, amino-terminal-pro-B-type natriuretic peptide.

Figure 2. Histograms of the numbers of participants in systolic (closed columns) and diastolic (open columns) blood pressure ranges for females and males with either low-moderate cardiovascular disease (CVD) risk (d15\% 5-year risk) or high CV risk ( $>15 \%$ 5-year risk, including participants with vascular disease) calculated from the Framingham risk score. ${ }^{16}$ Blood pressure values are the mean of measurements at visit 1 and visit 2 for 3200 participants, and the mean values for visit 1 for the remainder of the 3847 participants.

Figure 3. Histograms of the numbers of participants in body mass index ranges for females and males without known diabetes or with diabetes on enrolment.

Figure 4. Histograms of the numbers of participants in serum low density lipoprotein cholesterol concentration ranges for females and males with either low-moderate cardiovascular disease (CVD) risk (d15\% 5-year risk) or high CV risk ( $>15 \%$ 5-year risk, including participants with vascular disease) calculated from the Framingham risk score. ${ }^{16}$

Figure 5. Histograms of the numbers of participants in HbAlc ranges for females and males without known diabetes or with diabetes on enrolment. 
Figure 6. Histograms of the numbers of participants in estimated glomerular filtration rate (eGFR) ranges for females and males with either low-moderate cardiovascular disease (CVD) risk (d15\% 5-year risk) or high CV risk ( $>15 \%$ 5-year risk, including participants with vascular disease) calculated from the Framingham risk score. ${ }^{16}$ 
Table 1. Characteristics of 3847 SCREEN-HF study participants

\begin{tabular}{|c|c|c|c|}
\hline Characteristic & Total & Women & Men \\
\hline & $\mathrm{n}=3847$ & $\mathrm{n}=1746$ & $\mathrm{n}=2101$ \\
\hline Age (years) & $69(65-75)$ & $69(65-75)$ & $70(65-75)$ \\
\hline Bupa member & $3528(92 \%)$ & $1603(92 \%)$ & $1925(92 \%)$ \\
\hline Systolic blood pressure (mmHg) & $140(130-150)$ & $138(128-150)$ & $141(132-151)$ \\
\hline Diastolic blood pressure (mmHg) & $79(73-85)$ & $79(72-85)$ & $79(73-85)$ \\
\hline Hypertension & $3294(86 \%)$ & $1576(90 \%)$ & $1718(82 \%)$ \\
\hline Diabetes & $703(18 \%)$ & $274(16 \%)$ & $429(20 \%)$ \\
\hline Previous myocardial infarction & $391(10 \%)$ & $88(5 \%)$ & $303(14 \%)$ \\
\hline Total ischaemic heart disease & $852(22 \%)$ & $243(14 \%)$ & $609(29 \%)$ \\
\hline Previous stroke or TIA & $421(11 \%)$ & $169(10 \%)$ & $252(12 \%)$ \\
\hline Peripheral vascular disease & $125(3 \%)$ & $32(2 \%)$ & $93(4 \%)$ \\
\hline Cardiovascular disease & $1209(31 \%)$ & $396(23 \%)$ & $813(39 \%)$ \\
\hline Atrial fibrillation & $393(10 \%)$ & $151(9 \%)$ & $242(12 \%)$ \\
\hline Pacemaker & $66(1.7 \%)$ & $18(1.0 \%)$ & $48(2.3 \%)$ \\
\hline Body mass index $\left(\mathrm{kg} / \mathrm{m}^{2}\right)$ & $28(25-31)$ & $28(25-32)$ & $28(25-31)$ \\
\hline Waist circumference $(\mathrm{cm})$ & 99 (91-107) & $94(86-103)$ & $103(96-110)$ \\
\hline Obstructive sleep apnoea & $279(7 \%)$ & $64(4 \%)$ & $215(10 \%)$ \\
\hline 5-year CVD risk $<10 \% *$ & $898(23 \%)$ & $810(47 \%)$ & $88(4 \%)$ \\
\hline 5-year CVD risk $10-15 \% *$ & $621(16 \%)$ & $316(18 \%)$ & $305(15 \%)$ \\
\hline 5 -year CVD risk $>15 \% \dagger$ & $2321(61 \%)$ & $615(35 \%)$ & $1706(81 \%)$ \\
\hline
\end{tabular}

Tobacco use: 


$\begin{array}{llll}\text { Current smoker } & 138(4 \%) & 59(3 \%) & 79(4 \%) \\ \text { Former smoker } & 1751(46 \%) & 588(34 \%) & 1163(55 \%) \\ \text { Non-smoker } & 1955(51 \%) & 1098(63 \%) & 857(41 \%) \\ \text { Alcohol }>2 \text { drinks/day } & 762(20 \%) & 145(8 \%) & 617(29 \%) \\ \text { Statin therapy } & 1993(52 \%) & 832(48 \%) & 1161(55 \%) \\ \text { Aspirin therapy } & 1603(42 \%) & 624(36 \%) & 979(47 \%) \\ \text { Clopidogrel therapy } & 240(6.2 \%) & 95(5.4 \%) & 145(6.9 \%) \\ \text { Aspirin and/or clopidogrel therapy) } & 1737(45 \%) & 687(39 \%) & 1050(50 \%) \\ \text { Warfarin therapy } & 178(4.6 \%) & 57(3.3 \%) & 121(5.8 \%) \\ \text { NSAID therapy } & 324(8 \%) & 152(9 \%) & 172(8 \%) \\ \end{array}$

Summary statistics are median (interquartile range) or $n(\%)$. Blood pressure values are the medians (interquartile range) for the average values for visits 1 and 2 for 3200 participants, and the mean values for visit 1 for the remainder of the 3847 participants. Total ischaemic heart disease refers to myocardial infarction, coronary revascularisation, coronary artery disease detected on coronary angiography, and angina. Cardiovascular disease refers to total ischaemic heart, cerebrovascular and peripheral vascular disease. CVD, cardiovascular disease; NSAID, non-steroidal anti-inflammatory drug; TIA, transient ischaemic attack. Data for cardiovascular disease, diabetes, obstructive sleep apnoea, smoking, alcohol intake and drug therapy were from self-report. Alcohol $>2$ drinks/day refers to consumption of more than 2 standard drinks on any day. ${ }^{46} 5$-year CV risk represents Framingham risk score. ${ }^{16} *$, excludes participants with vascular disease; $\uparrow$, includes participants with vascular disease. 
Table 2. Biochemistry of SCREEN-HF study participants

\begin{tabular}{|c|c|c|c|}
\hline Characteristic & Total & Women & Men \\
\hline NT-proBNP (pmol/l) & $12.1(6.3-23.7)$ & $14.2(7.8-26.2)$ & $10.3(5.2-21.1)$ \\
\hline $\mathrm{eGFR}\left(\mathrm{ml} / \mathrm{min} / 1.73 \mathrm{~m}^{2}\right)$ & $72(61-83)$ & $70(60-82)$ & $74(63-84)$ \\
\hline Non-fasting glucose $(\mathrm{mmol} / \mathrm{l})$ & $5.6(5.0-6.7)$ & $5.5(5.0-6.5)$ & $5.7(5.0-6.8)$ \\
\hline HbA1c (\%) & $5.6(5.4-5.9)$ & $5.6(5.4-5.8)$ & $5.6(5.4-5.9)$ \\
\hline Total cholesterol (mmol/l) & $4.8(4.1-5.5)$ & $5.1(4.5-5.9)$ & $4.5(3.8-5.2)$ \\
\hline Triglyceride (mmol/l) & $1.5(1.1-2.1)$ & $1.5(1.1-2.0)$ & $1.6(1.1-2.2)$ \\
\hline
\end{tabular}

High density lipoprotein cholesterol (mmol/l)

$$
1.2(1.0-1.5) \quad 1.4(1.1-1.7) \quad 1.1(0.9-1.4)
$$

Low density lipoprotein cholesterol (mmol/l)

$$
2.7(2.1-3.4) \quad 2.9(2.3-3.6) \quad 2.5(1.9-3.2)
$$

Summary statistics are median (interquartile range), $n=1744$ women and $n=2098$ men for NT-proBNP, eGFR and non-fasting glucose; n=1287 women and n=1635 men for HbA1c; $n=1361$ women and $n=1715$ men for lipids. eGFR, estimated glomerular filtration rate; NTproBNP, amino-terminal-pro-B-type natriuretic peptide. 


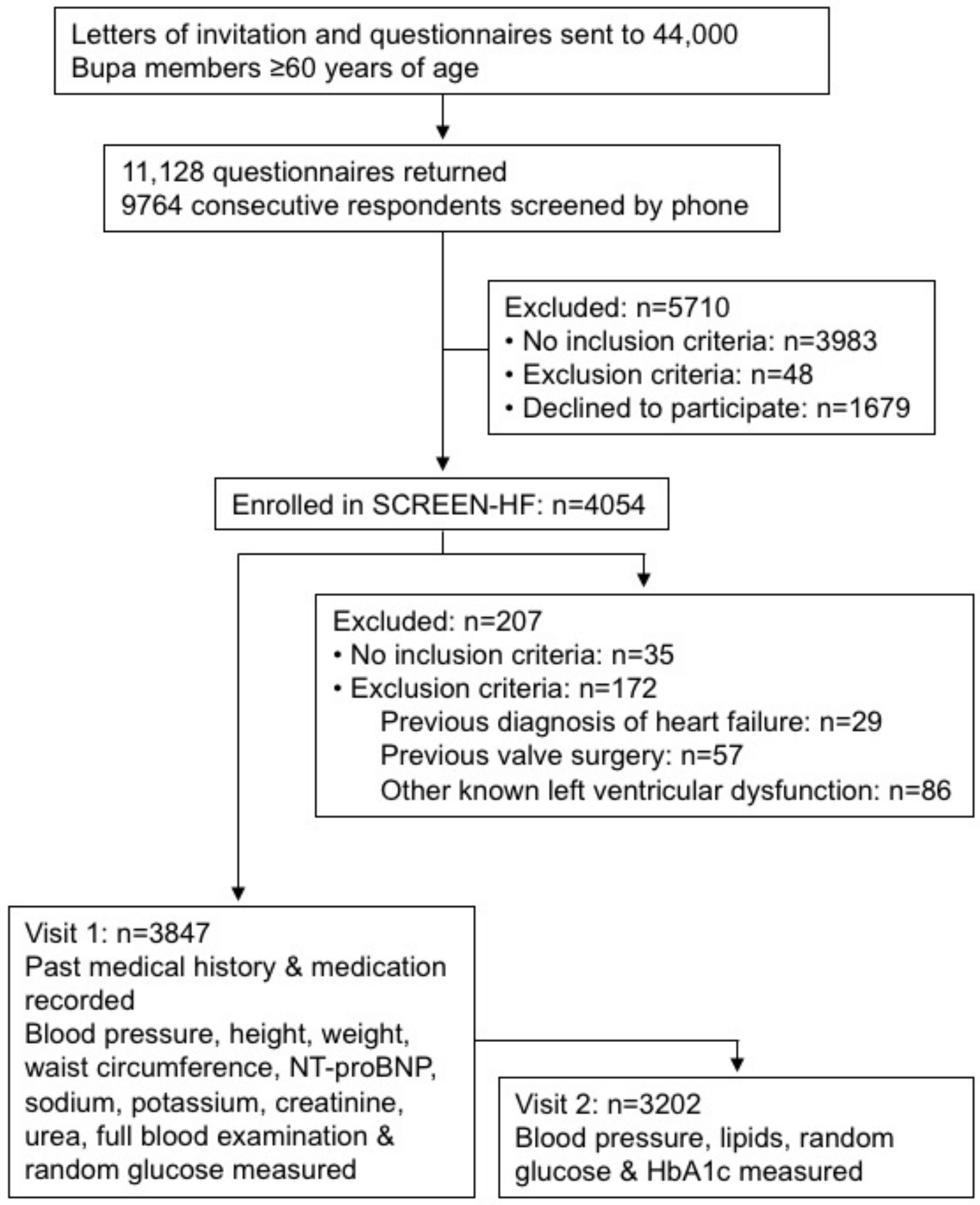

Figure 1. Flow chart of numbers of individuals invited to participate in the SCReening Evaluation of the Evolution of New Heart Failure study who were subsequently enrolled and attended visits 1 and 2. NT-proBNP, amino-terminal-pro-B-type natriuretic peptide. 

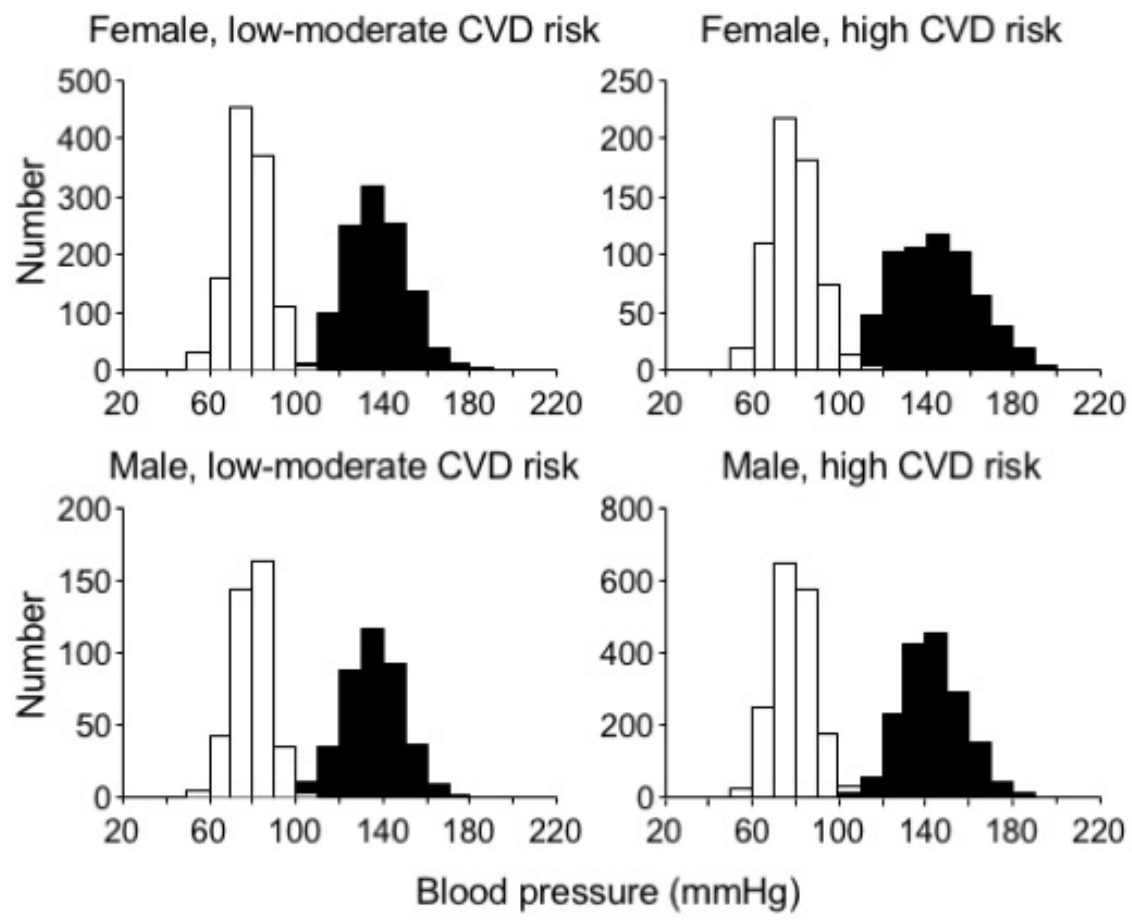

Figure 2. Histograms of the numbers of participants in systolic (closed columns) and diastolic (open columns) blood pressure ranges for females and males with either low-moderate cardiovascular disease (CVD) risk (d15\% 5-year risk) or high CVD risk (>15\% 5-year risk, including participants with vascular disease) calculated from the Framingham risk score. ${ }^{16}$ Blood pressure values are the mean of measurements at visit 1 and visit 2 for 3200 participants, and the mean values for visit 1 for the remainder of the 3847 participants. 

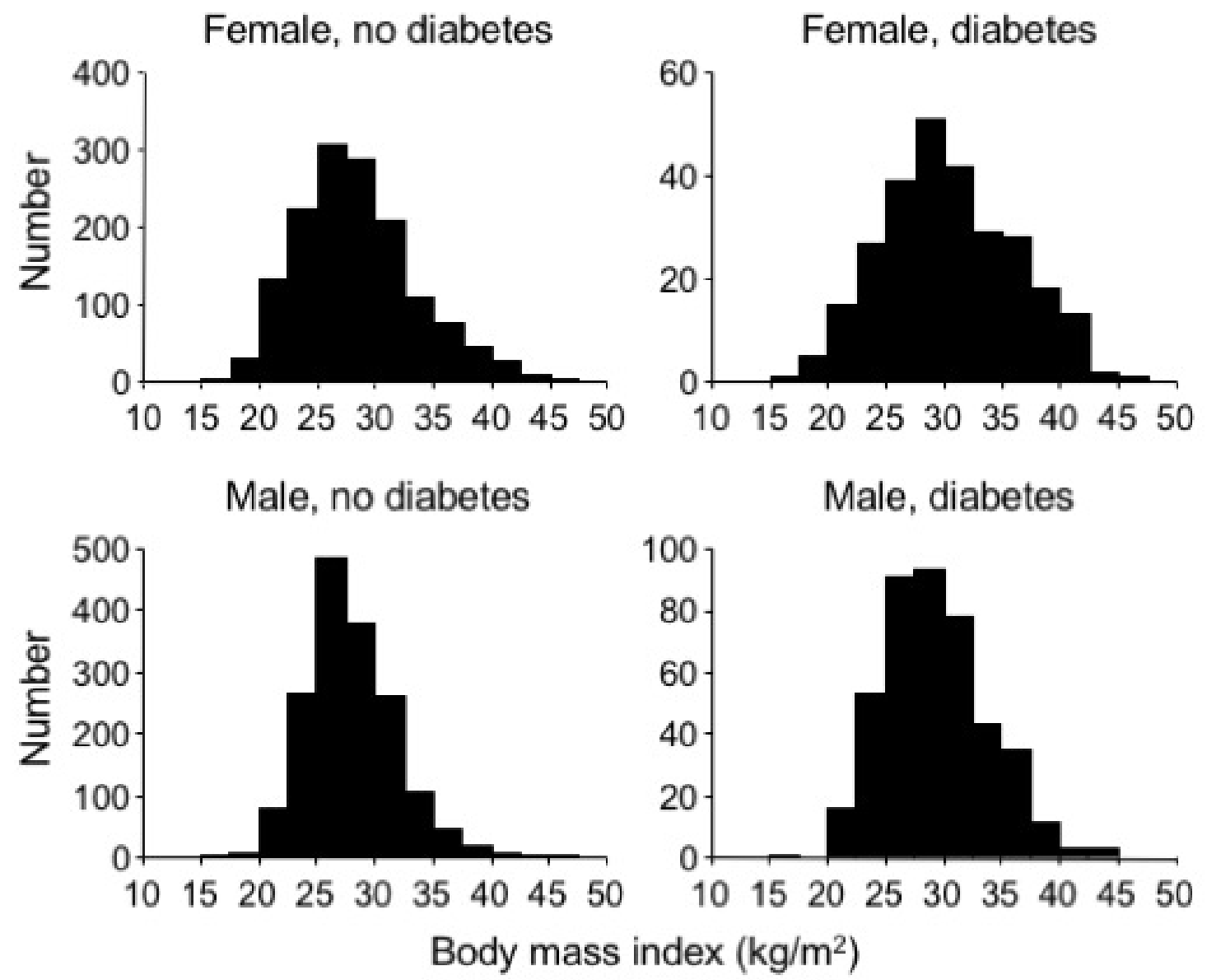

Figure 3. Histograms of the numbers of participants in body mass index ranges for females and males without known diabetes or with diabetes on enrolment. 

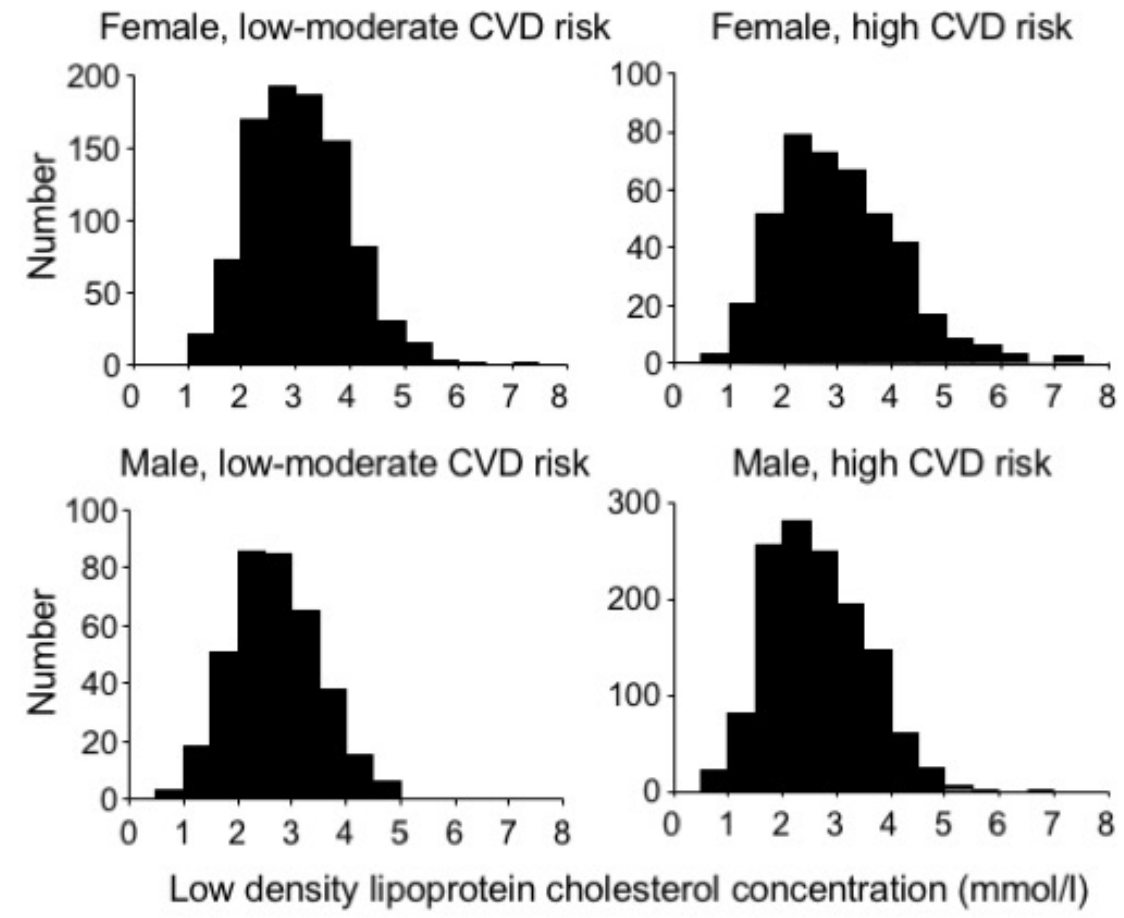

Figure 4. Histograms of the numbers of participants in serum low density lipoprotein cholesterol concentration ranges for females and males with either low-moderate cardiovascular disease (CVD) risk (d15\% 5-year risk) or high CVD risk (>15\% 5-year risk, including participants with vascular disease) calculated from the Framingham risk score. ${ }^{16}$ 
Female, no diabetes

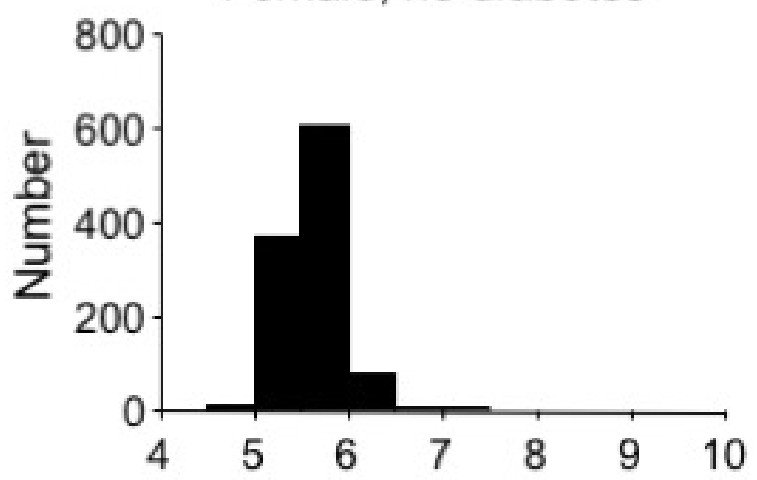

Male, no diabetes

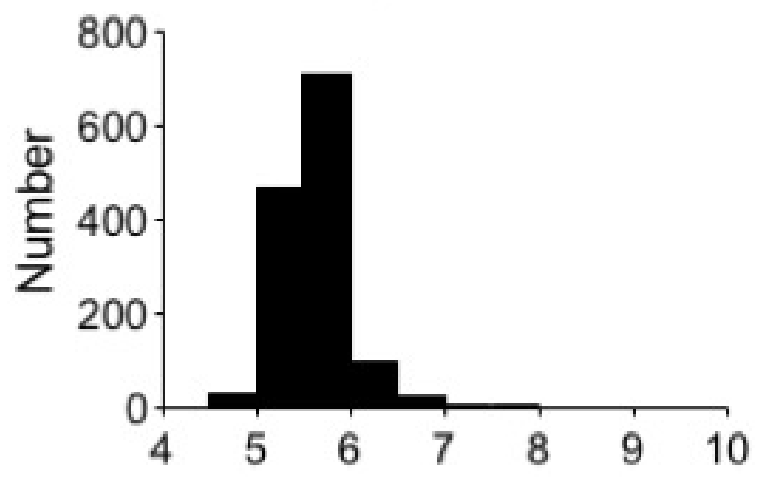

Female, diabetes

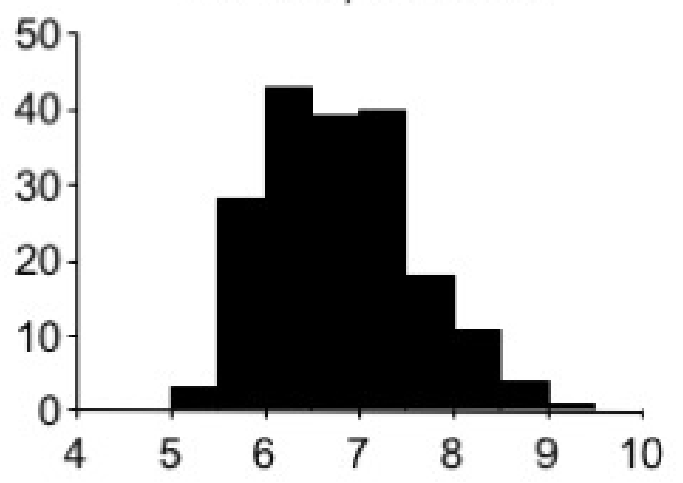

Male, diabetes

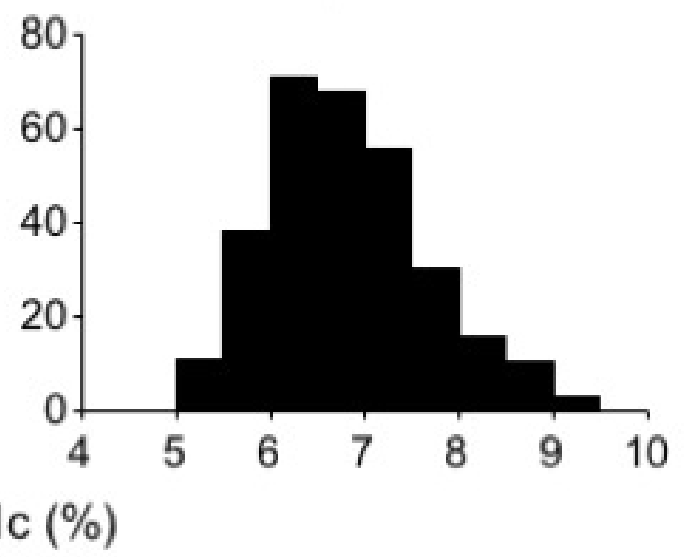

Figure 5. Histograms of the numbers of participants in HbAlc ranges for females and males without known diabetes or with diabetes on enrolment. 
Female, low-moderate CVD risk Female, high CVD risk
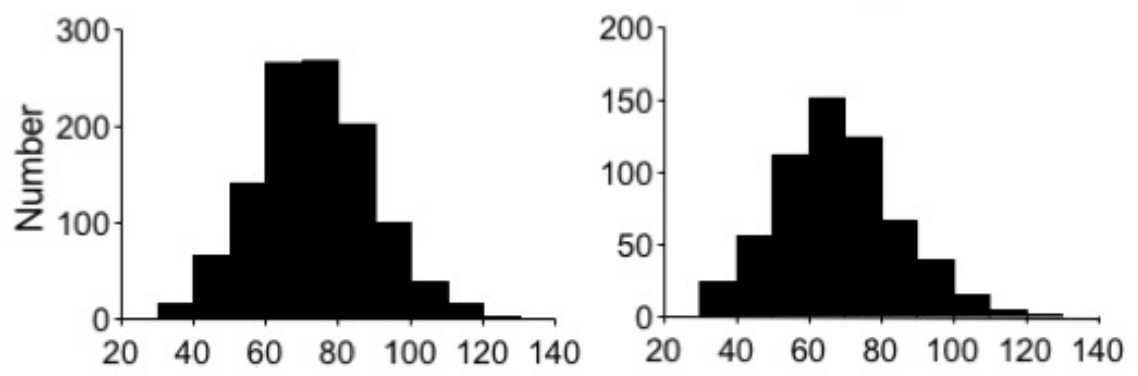

Male, low-moderate CVD risk

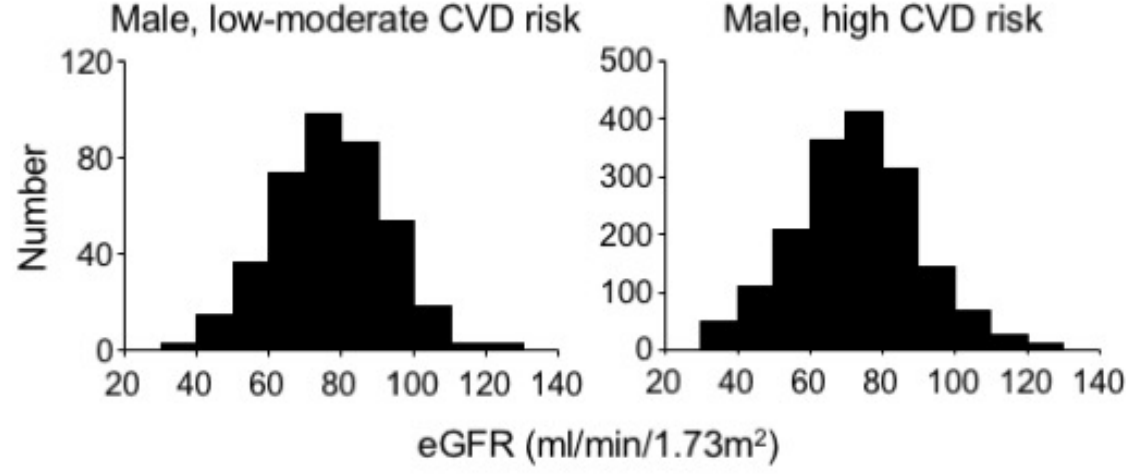

Figure 6. Histograms of the numbers of participants in estimated glomerular filtration rate (eGFR) ranges for females and males with either low-moderate cardiovascular disease (CVD) risk (d15\% 5-year risk) or high CVD risk (>15\% 5-year risk, including participants with vascular disease) calculated from the Framingham risk score. ${ }^{16}$ 
Table 1. Characteristics of 3847 SCREEN-HF study participants

\begin{tabular}{|c|c|c|c|}
\hline Characteristic & Total & Women & Men \\
\hline & $\mathrm{n}=3847$ & $n=1746$ & $\mathrm{n}=2101$ \\
\hline Age (years) & $69(65-75)$ & $69(65-75)$ & $70(65-75)$ \\
\hline Bupa member & $3528(92 \%)$ & $1603(92 \%)$ & $1925(92 \%)$ \\
\hline Systolic blood pressure (mmHg) & $140(130-150)$ & $138(128-150)$ & $141(132-151)$ \\
\hline Diastolic blood pressure $(\mathrm{mmHg})$ & $79(73-85)$ & $79(72-85)$ & $79(73-85)$ \\
\hline Hypertension & $3294(86 \%)$ & $1576(90 \%)$ & $1718(82 \%)$ \\
\hline Diabetes & $703(18 \%)$ & $274(16 \%)$ & $429(20 \%)$ \\
\hline Previous myocardial infarction & $391(10 \%)$ & $88(5 \%)$ & $303(14 \%)$ \\
\hline Total ischaemic heart disease & $852(22 \%)$ & $243(14 \%)$ & $609(29 \%)$ \\
\hline Previous stroke or TIA & $421(11 \%)$ & $169(10 \%)$ & $252(12 \%)$ \\
\hline Peripheral vascular disease & $125(3 \%)$ & $32(2 \%)$ & $93(4 \%)$ \\
\hline Cardiovascular disease & $1209(31 \%)$ & $396(23 \%)$ & $813(39 \%)$ \\
\hline Atrial fibrillation & $393(10 \%)$ & $151(9 \%)$ & $242(12 \%)$ \\
\hline Pacemaker & $66(1.7 \%)$ & $18(1.0 \%)$ & $48(2.3 \%)$ \\
\hline Body mass index $\left(\mathrm{kg} / \mathrm{m}^{2}\right)$ & $28(25-31)$ & $28(25-32)$ & $28(25-31)$ \\
\hline Waist circumference $(\mathrm{cm})$ & $99(91-107)$ & $94(86-103)$ & $103(96-110)$ \\
\hline Obstructive sleep apnoea & $279(7 \%)$ & $64(4 \%)$ & $215(10 \%)$ \\
\hline 5-year CVD risk $<10 \% *$ & $898(23 \%)$ & $810(47 \%)$ & $88(4 \%)$ \\
\hline 5-year CVD risk $10-15 \% *$ & $621(16 \%)$ & $316(18 \%)$ & $305(15 \%)$ \\
\hline 5-year CVD risk $>15 \% \dagger$ & $2321(61 \%)$ & $615(35 \%)$ & $1706(81 \%)$ \\
\hline
\end{tabular}

Tobacco use: 


\begin{tabular}{llll} 
Current smoker & $138(4 \%)$ & $59(3 \%)$ & $79(4 \%)$ \\
Former smoker & $1751(46 \%)$ & $588(34 \%)$ & $1163(55 \%)$ \\
Non-smoker & $1955(51 \%)$ & $1098(63 \%)$ & $857(41 \%)$ \\
Alcohol $>2$ drinks/day & $762(20 \%)$ & $145(8 \%)$ & $617(29 \%)$ \\
Statin therapy & $1993(52 \%)$ & $832(48 \%)$ & $1161(55 \%)$ \\
Aspirin therapy & $1603(42 \%)$ & $624(36 \%)$ & $979(47 \%)$ \\
Clopidogrel therapy & $240(6.2 \%)$ & $95(5.4 \%)$ & $145(6.9 \%)$ \\
Aspirin and/or clopidogrel therapy $1737(45 \%)$ & $687(39 \%)$ & $1050(50 \%)$ \\
Warfarin therapy & $178(4.6 \%)$ & $57(3.3 \%)$ & $121(5.8 \%)$ \\
NSAID therapy & $324(8 \%)$ & $152(9 \%)$ & $172(8 \%)$ \\
& & & \\
\hline
\end{tabular}

Summary statistics are median (interquartile range) or $\mathrm{n}(\%)$. Blood pressure values are the medians (interquartile range) for the average values for visits 1 and 2 for 3200 participants, and the mean values for visit 1 for the remainder of the 3847 participants. Total ischaemic heart disease refers to myocardial infarction, coronary revascularisation, coronary artery disease detected on coronary angiography, and angina. Cardiovascular disease refers to total ischaemic heart, cerebrovascular and peripheral vascular disease. CVD, cardiovascular disease; NSAID, non-steroidal anti-inflammatory drug; TIA, transient ischaemic attack. Data for cardiovascular disease, diabetes, obstructive sleep apnoea, smoking, alcohol intake and drug therapy were from self-report. Alcohol $>2$ drinks/day refers to consumption of more than 2 standard drinks on any day. ${ }^{46} 5$-year CV risk represents Framingham risk score. ${ }^{16} *$, excludes participants with vascular disease; $\uparrow$, includes participants with vascular disease. 
Table 2. Biochemistry of SCREEN-HF study participants

\begin{tabular}{llll} 
Characteristic & Total & Women & Men \\
\hline NT-proBNP $(\mathrm{pmol} / \mathrm{l})$ & $12.1(6.3-23.7)$ & $14.2(7.8-26.2)$ & $10.3(5.2-21.1)$ \\
eGFR $\left(\mathrm{ml} / \mathrm{min} / 1.73 \mathrm{~m}^{2}\right)$ & $72(61-83)$ & $70(60-82)$ & $74(63-84)$ \\
Non-fasting glucose $(\mathrm{mmol} / \mathrm{l})$ & $5.6(5.0-6.7)$ & $5.5(5.0-6.5)$ & $5.7(5.0-6.8)$ \\
HbAlc $(\%)$ & $5.6(5.4-5.9)$ & $5.6(5.4-5.8)$ & $5.6(5.4-5.9)$ \\
Total cholesterol $(\mathrm{mmol} / \mathrm{l})$ & $4.8(4.1-5.5)$ & $5.1(4.5-5.9)$ & $4.5(3.8-5.2)$ \\
Triglyceride $(\mathrm{mmol} / \mathrm{l})$ & $1.5(1.1-2.1)$ & $1.5(1.1-2.0)$ & $1.6(1.1-2.2)$
\end{tabular}

High density lipoprotein cholesterol ( $\mathrm{mmol} / \mathrm{l})$

$$
1.2(1.0-1.5) \quad 1.4(1.1-1.7) \quad 1.1(0.9-1.4)
$$

Low density lipoprotein cholesterol (mmol/l)

$$
2.7(2.1-3.4) \quad 2.9(2.3-3.6) \quad 2.5(1.9-3.2)
$$

Summary statistics are median (interquartile range), $n=1744$ women and $n=2098$ men for NT-proBNP, eGFR and non-fasting glucose; $n=1287$ women and n=1635 men for HbA1c; $n=1361$ women and $n=1715$ men for lipids. eGFR, estimated glomerular filtration rate; NTproBNP, amino-terminal-pro-B-type natriuretic peptide. 


\section{University Library}

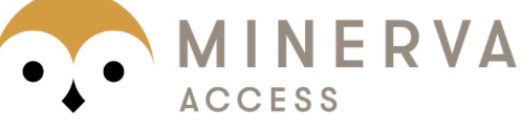

A gateway to Melbourne's research publications

Minerva Access is the Institutional Repository of The University of Melbourne

Author/s:

Campbell, DJ;Coller, JM;Gong, FF;McGrady, M;Prior, DL;Boffa, U;Shiel, L;Liew, D;Wolfe, R;Owen, AJ;Krum, H;Reid, CM

Title:

Risk factor management in a contemporary Australian population at increased cardiovascular disease risk

Date:

2018-06-01

Citation:

Campbell, D. J., Coller, J. M., Gong, F. F., McGrady, M., Prior, D. L., Boffa, U., Shiel, L., Liew, D., Wolfe, R., Owen, A. J., Krum, H. \& Reid, C. M. (2018). Risk factor management in a contemporary Australian population at increased cardiovascular disease risk. INTERNAL MEDICINE JOURNAL, 48 (6), pp.688-698. https://doi.org/10.1111/imj.13678.

Persistent Link:

http://hdl.handle.net/11343/283434 